
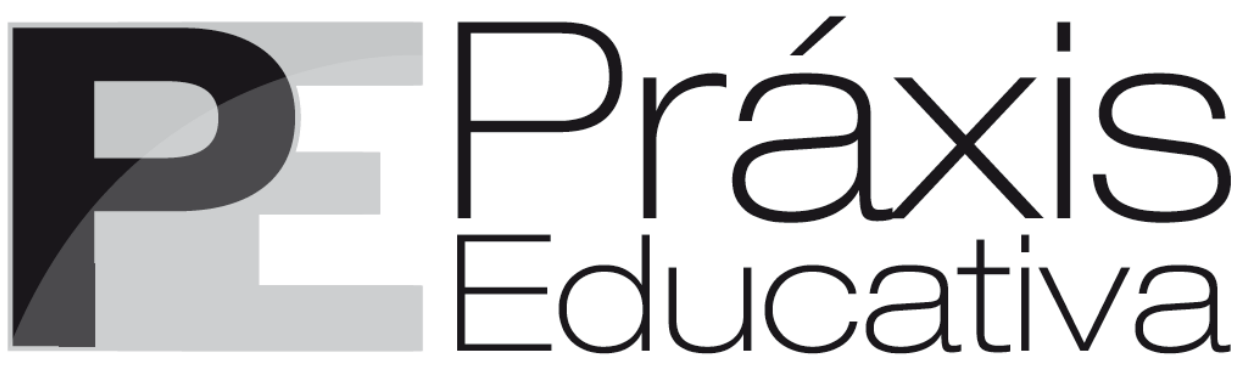

ISSN 1809-4309 (Versão online) DOI: 10.5212/PraxEduc.v.11i3.0007

\title{
Os impactos da avaliação em larga escala nos currículos escolares*
}

\section{The impacts of large-scale assessment on school curriculum}

\section{Los impactos de la evaluación a gran escala en los currículos escolares}

\author{
Rita de Cássia Silva Godoi Menegão*
}

\begin{abstract}
Resumo: Este trabalho resulta de uma pesquisa de doutorado que analisa o currículo escolar na interface com a avaliação externa, com o objetivo de identificar, descrever e analisar como os sujeitos estão se posicionando nesse contexto de testes, e mapear as alterações realizadas no currículo escolar, impelidas pela Prova Brasil e IDEB. A abordagem é descritivo-analítica, com uso da análise documental, questionário e entrevistas orais, em amostra de 55 professores, sujeitos. A investigação fundamentou-se em Freitas et al. (2012), Gimeno Sacristán (2000), Apple (2005), Sousa (2004) entre outros. A avaliação externa tem impactado a configuração do currículo escolar e induzido ao treinamento, em demasia, para os testes, comprometendo, desta forma, a qualidade da educação.
\end{abstract}

Palavras-chave: Currículo escolar. Avaliação externa em larga escala. Políticas educacionais.

\begin{abstract}
This work results from a doctoral research which analyzed the curriculum at the interface with the external evaluation in order to identify, describe and analyze how the subjects are positioning themselves in this context of tests, and map the changes made in the school curriculum driven by Prova Brasil and IDEB. The approach is descriptive and analytical, using documentary analysis, questionnaire and oral interviews in a sample of 55 teachers, subjects. The investigation was based on Freitas and colleagues (2012), Gimeno Sacristán (2000), Apple (2005), Sousa (2004) among others. The external evaluation has impacted the setting of the school curriculum and induced to over training for tests, thus compromising the quality of education.
\end{abstract}

Keywords: School curriculum. Large scale external evaluation. Educational policies.

Resumen: Este trabajo resulta de una investigación de Doctorado que analizó el currículo escolar en la interfaz con la evaluación externa, con el objetivo de identificar, describir y analizar como los sujetos se están posicionando en ese contexto de pruebas y para mapeo de las alteraciones realizadas en el currículo escolar, y estimuladas por la Prova Brasil e IDEB. El abordaje es descriptivo y analítico, utilizando análisis documental, cuestionario y entrevistas orales, en una muestra de 55 profesores, sujetos. La investigación se basó en Freitas et al. (2012), Gimeno Sacristán (2000), Apple (2005), Sousa (2004), entre otros. La evaluación externa ha impactado la configuración del currículo escolar e inducido al entrenamiento demasiado para las pruebas, comprometiendo, de esa forma, la calidad de la educación.

Palabras clave: Currículo escolar. Evaluación externa a gran escala. Políticas educacionales.

\footnotetext{
* Financiamento: Fundação de Amparo à Pesquisa do Estado de Mato Grosso - FAPEMAT.

** Professora da Educação Básica do Estado de Mato Grosso e Município de Cuiabá - Doutora em Educação pela Faculdade de Educação da Universidade Estadual de Campinas (UNICAMP). Prof a orientadora: Maria Márcia Sigrist Malavasi - UNICAMP. E-mail: <ritamenegao@gmail.com>.
} 


\section{Introdução}

Este trabalho aborda a avaliação externa em larga escala na interface com o currículo escolar. Partimos do pressuposto de que as políticas de avaliação têm caráter regulador e servem, dentre outros, para demarcar o que deve ser valorizado e ensinado nas escolas, uma vez que seu formato apresenta forte potencial indutor. No entanto, também pressupomos que toda política, ao ser implementada, está sujeita a modificações, seja pela interpretação e recriação dos sujeitos, ou pelas condições estruturais e culturais que as materializam. Neste sentido, consideramos imprescindível analisar como as políticas de avaliação externa estão se concretizando nas escolas.

Logo, saber quais as finalidades que os testes dessa avaliação buscam, para qual formação contribuem, e com quais interesses estão alinhados são indagações que necessitam ser esclarecidas. Embora a literatura da área venha apontando os riscos que essas avaliações trazem, elas permanecem, e já estão em sua terceira geração. Diante da sedimentação dessas políticas e ao mesmo tempo compreendendo as singularidades dos contextos em que essas avaliações ocorrem, buscamos responder: Como a avaliação externa está se materializando na escola e no currículo escolar? Que alterações os professores afirmam ter se configurado nos currículos escolares nesse contexto de testes? Temos por objetivo identificar, descrever e analisar como os sujeitos estão se posicionando diante do quadro delineado, e mapear as alterações que alegam realizar nos currículos escolares impelidas pela Prova Brasil/IDEB.

Partimos da premissa de que, além das especificidades que cada um dos contextos escolares apresenta, os conceitos, valores, procedimentos e atitudes que os professores possuem também exercem o importante papel de fundamentar e orientar sua prática em relação à política de avaliação. Assim, definimos por objeto de estudo a avaliação externa em larga escala (PB/IDEB) na interface com o currículo escolar, a partir das percepções dos professores.

Os instrumentos e sujeitos foram definidos de forma a garantir a voz dos envolvidos no processo da política de avaliação, pois acreditamos que o conhecimento da realidade, a partir dos olhares de quem a vivencia no cotidiano, pode assegurar melhor compreensão do contexto. Assim, a amostra foi composta por cinquenta e cinco (55) professores efetivos que lecionavam nas turmas de $5^{\circ}$ ano, no ano letivo de 2013, nas escolas urbanas da rede municipal de educação de Cuiabá-MT.

Optamos pela pesquisa com enfoque descritivo-analítico, fundamentados na análise de conteúdo proposta por Bardin (2012), envolvendo a análise documental, questionário e entrevista semiestruturada.

Embora tenhamos conseguido a contribuição de muitos sujeitos, o que equivale declarar que obtivemos um volume numeroso de ricas informações que possibilitou a constituição de um corpus de análise significativo, ainda assim, não podemos declarar que finalizaremos todos os argumentos em torno das teses que o objeto suscita.

\section{O protagonismo da avaliação externa nos contextos escolares}

A avaliação sempre ocupou lugar de destaque nas atividades educativas, quer se trate da avaliação de aprendizagens, dos sistemas ou das redes de ensino. Nesse sentido, não houve estranhamento de nossa parte ao constatar no campo, lócus da pesquisa, a repercussão que a avaliação externa em larga escala - Prova Brasil (PB) e o Índice de Desenvolvimento da Educação Básica (IDEB) - tem no cotidiano escolar das unidades escolares e nas práticas pedagógicas de todos os sujeitos com os quais dialogamos.

Práxis Educativa, Ponta Grossa, p. 641-656, v. 11, n. 3, set./dez. 2016 Disponível em: <http://www.revistas2.uepg.br/index.php/praxiseducativa> 
Avaliação externa em larga escala a que nos referimos diz respeito à avaliação realizada na escola, mas elaborada fora dela, e a expressão em larga escala refere-se à abrangência e extensão alcançadas (DURLI; SCHNEIDER, 2010). Compreende testes e exames aplicados a um conjunto de estudantes, escolas e redes de ensino, dependendo dos objetivos a que se destinam. Para Soares e Xavier (2013, p. 915), "com o IDEB a expressão concreta do direito a aprender passa a ser a evidência fornecida pelo resultado da Prova Brasil". Assim, os testes da avaliação externa em larga escala ganham credibilidade como facilmente quantificáveis e comparáveis.

Compreendemos, referendando-nos em Freitas et al. (2012), que os testes surgem fundamentados por pressupostos que orientam políticas de racionalização, ou seja, utilizar investimentos mínimos e obter eficiência máxima dos sistemas. Estes, por sua vez, induzem a um tipo específico de ação avaliativa: aferir o produto, em outras palavras, medir resultados em detrimento da compreensão dos processos e dos contextos em que ocorrem.

Entendemos igualmente que os números, apesar de aparentemente neutros e apresentados como verdades inquestionáveis, também são de natureza política, pois a escolha de como e o que medir é uma decisão de dimensão política. Nessa perspectiva em que os números centralizam os debates e as ações políticas, "devido à inquestionável objetividade que os números parecem evidenciar, sua utilização termina despolitizando os debates que pressupõem julgamentos políticos", fazendo com que outras dimensões dos problemas deixem de ser questionadas (ROSE, 1999 apud SANTOS, 2013, p. 112).

\section{Currículo do Ensino Fundamental: com qual matriz formativa?}

A avaliação em larga escala propõe medir a qualidade da educação escolar. Torna-se, nesse caso, necessário saber de que concepção de qualidade e de educação se trata. Tendo esse ponto esclarecido, ainda se necessita saber com qual currículo se vai atuar. Questionamentos esses que, mormente, levam-nos a indagar sobre que conhecimentos devem ser ensinados nas escolas. Isso porque nessas definições estará explicitada, ou implícita, a expressão de uma concepção de mundo, de homem e de sociedade e, assim, a qualidade que se almeja.

O trabalho escolar ministrado nas escolas, com o advento da avaliação externa, está sendo capaz de potencializar as múltiplas dimensões dos estudantes? Que perspectiva de homem e de sociedade o currículo escolar, configurado em contextos avaliativos, propõe à formação?

O foco no currículo escolar se deve à compreensão que, tanto o currículo quanto a avaliação da educação são resultantes de um complexo entrelaçamento dos aspectos sociais, culturais, econômicos e políticos, no qual se encontra amalgamada a forma escola, intrinsecamente. De antemão sabemos que determinada seleção de conhecimentos, mediante ampla gama de possibilidades para se definir o currículo, nunca é arbitrária, mas decorrente da valorização da ideologia de um ou vários grupos estabelecidos.

Historicamente, no Brasil, o currículo tem sido, em grande parte, fruto do pensamento e ideologia dos grupos dominantes, que estabelecem conteúdos, habilidades e crenças que consideram importantes inculcar nos estudantes por meio das escolas. Ousamos afirmar que favorecer a totalidade da população escolar com educação de qualidade social não tem sido o escopo das políticas curriculares e, quiçá, de avaliação.

Disso resulta que os conhecimentos propostos curricularmente não são atemporais e eternos; ao contrário, muitas vezes são respostas aos interesses e necessidades historicamente situados, que corporificam a reprodução das desigualdades e privilégios, como entende Bourdieu

Práxis Educativa, Ponta Grossa, p. 641-656, v. 11, n. 3, set./dez. 2016 Disponível em: <http://www.revistas2.uepg.br/index.php/praxiseducativa> 
(1992). Entretanto, o poder e a dominação associada ao currículo não significam o subjugo mecânico, em que estudantes e professores são passivos receptores de conteúdo, atitudes e costumes. Nesse processo, conflitos e resistências podem ocorrer, de onde vem nossa afirmação de currículo como campo permanente de disputas e tensões.

O conhecimento tem uma dinâmica que se mistura com a própria vida. Assim, há um permanente movimento em busca de se conhecer mais e/ou ampliar e aprofundar conhecimentos já existentes. Desse modo, eles são expressam de formas distintas em culturas e momentos históricos diferentes. Neste sentido, elencamos alguns diálogos dos autores da área de currículo e suas respectivas versões acerca das ocorrências e/ou manifestações curriculares, ou seja, algumas das tentativas de conceber o conhecimento a partir de poucas teorias pedagógicas que marcaram as últimas décadas. Afinal, o currículo é a matéria-prima do processo educativo, e a forma de entendê-lo serve de orientação para eleger conteúdos, metodologia, avaliação e outros que, entrelaçados, consubstanciam a formação do estudante.

Não há consenso em relação ao que seja currículo. Se tomarmos as discussões teóricas que se travam a esse respeito, veremos perspectivas completamente adversas. De acordo com Pacheco (2003, p. 6), o currículo é, cumulativamente, uma intenção e uma realidade que ocorrem em um contexto determinado, e que resulta de decisões tomadas em vários contextos. Nesta direção, o autor afirma que o currículo é um projeto que diz respeito a professores e alunos, mas abrange todos os intervenientes que, direta ou indiretamente, participam na sociedade do conhecimento ou sociedade da aprendizagem.

Há os teóricos que entendem que as características da sociedade da comunicação e da informação influenciam diretamente o campo educacional. Deste modo, as políticas da Educação Básica, tomando por conjectura que a educação atualmente ocupa, "[...] junto com as políticas de ciência e tecnologia, lugar nuclear nas decisões macropolíticas do Estado em termos de formação de recursos humanos exigidos pelo padrão de reestruturação produtiva" (CASTRO; LAUANDE, 2009, p. 145).

Goodson (2007) lembra que alianças entre prescrição e poder foram, ao longo dos anos, cuidadosamente cunhadas, de forma a transformar o currículo em um mecanismo de reprodução das relações de poder existentes na sociedade.

Diante das posições apresentadas, o currículo pode ser entendido como um significativo instrumento utilizado nos mais diferentes tempos e sociedades, tanto para desenvolver processos de conservação, como de transformação e renovação dos conhecimentos historicamente acumulados e, assim, socializar os alunos segundo valores tidos como desejáveis. Todavia, há sempre que se perguntar: desejáveis para quem?

Nesse sentido, os currículos da Educação Básica, que se pautam na ideia dos resultados de aprendizagem a serem alcançados e na exigência do desempenho docente, partem do princípio que:

[...] assume também as exigências da ordem social desenvolvida nos processos de trabalho, tais como disciplina, exatidão, submissão física, técnica e moral, cumprimento estrito dos deveres, pontualidade contenção corporal e efetiva. Ela assume os deveres impostos pela produção, através dos mecanismos do Estado, e relega a segundo plano, sob mil artifícios ideológicos, o direito à educação que fundamenta as demandas da sociedade civil. (CIAVATTA, 2002, p. 128).

Contudo, convém assinalar que, tendo perspectivas similares ou diferenciadas, os teóricos de currículo Apple (2005), Goodson (2007) e Young (2011) não se colocam favoráveis aos testes 
padronizados de desempenho e suas respectivas influências nos currículos escolares. Os pressupostos assinalados pelos autores citados devem ser continuamente alvo de debates, para que não se corra o risco de naturalizar uma pseudo harmonia social, ou até mesmo um aparente consenso político-ideológico. Pois o currículo escolar, apesar de ancorar-se em teorias curriculares que se diferenciam, ao

\begin{abstract}
Privilegiar um tipo de conhecimento é uma operação de poder. Destacar entre as múltiplas possibilidades, uma identidade ou subjetividade como sendo a ideal é uma operação de poder. As teorias do currículo não estão, nesse sentido, situadas num campo "puramente" epistemológico, de competição entre "puras" teorias. As teorias do currículo estão ativamente envolvidas na atividade de garantir o consenso, de obter hegemonia. (SILVA, 2007, p. 16, grifos do autor).
\end{abstract}

Reafirmamos que o currículo é sempre resultante de uma tradição seletiva, o que retira de seu bojo a pretensão de neutralidade, posto que seja fruto de relações de poder, emana da escolha de alguém, ou grupo(s) e da sua(s) respectiva(s) visão(ões) acerca do mundo e do que seja conhecimento legítimo. O currículo, assim entendido, representa um produto das tensões, dos conflitos e das concessões culturais, políticas e econômicas que (des)organizam um povo (APPLE, 2005). Desse modo, reiteramos que o currículo é um campo em constante disputa.

Para análise deste trabalho, compreendemos o currículo

[...] como processo, que envolve uma multiplicidade de relações, abertas ou tácitas, em diversos âmbitos, que vão da prescrição à ação, das decisões administrativas às práticas pedagógicas, na escola como instituição e nas unidades escolares especificamente. Para compreendê-lo e, principalmente, para elaborá-lo e implementá-lo de modo a transformar o ensino, é preciso refletir sobre grandes questões. (GIMENO SACRISTAN, 2000, p. 124).

\title{
Avaliação externa e currículo escolar: percepções dos professores
}

Dialogamos com 55 sujeitos, professores efetivos que ministraram aulas nos $5^{\circ}$ anos, no ano letivo de 2013, procurando entender como eles compreendem as avaliações externas, e também para mapear as alterações no currículo escolar, que os professores atribuem à avaliação em larga escala. Nessa direção, 64\% dos sujeitos admitiram que as alterações ocorreram na elaboração e no planejamento anual do $2^{\circ}$ ciclo; $74 \%$ disseram que foi no plano de ensino; $72,2 \%$, na metodologia utilizada, e 40,7\% , na organização dos alunos em sala (individual, grupo, duplas, etc.); e 83,9\% admitiram ser na avaliação da aprendizagem (mais provas, tipos de provas e simulados). Vale ressaltar que nenhum dos sujeitos afirmou não houve qualquer alteração. Este dado, a nosso ver, é bastante significativo para situarmos o invasivo bombardeio da PB/IDEB nos contextos escolares.

A primeira inquietação reportou-se ao planejamento curricular elaborado no início do ano letivo e aos respectivos planos de ensino; assim, saber qual material deu suporte para elaborá-los foi uma das preocupações. Do total, 92,5\% afirmaram que utilizaram os livros didáticos; 90,7\% utilizaram as sugestões da Matriz Curricular enviada pela SME/Cuiabá (MC); 77,7\%, os PCN; $74 \%$, as questões da Prova Brasil (PB); e 72,2\%, Indicadores da Matriz de Referência da Avaliação (MCR).

O currículo, em seu processo de desenvolvimento, segundo Gimeno Sacristán (2000, p. 105), passa por seis fases ou níveis de objetivação. O primeiro nível é o currículo prescrito, que serve como ponto de partida para elaboração de materiais, controle de sistemas, pois são os aspectos que atuam como referenciais para sistematizar o currículo; o segundo é denominado o currículo

Práxis Educativa, Ponta Grossa, p. 641-656, v. 11, n. 3, set./dez. 2016 Disponível em: < http://www.revistas2.uepg.br/index.php/praxiseducativa > 
apresentado aos professores, e inclui os conteúdos do currículo prescrito interpretado por diferentes e variadas instâncias. Para o autor, é o livro-texto didático detentor do papel mais decisivo neste nível.

Os dados permitem afirmar a importância dos livros didáticos para os sujeitos. Entretanto, considerando que a MC da SME e MCR da PB pertencem a esse nível, ou seja, a tradução do currículo para as escolas e professores, considerando o percentual de $90,7 \%$ dos sujeitos desta investigação que admitiram utilizá-las, fica expressa a ascensão e o lugar que esses materiais vêm ocupando na configuração do currículo escolar.

Ao acatar esses materiais como curriculares, eles se tornam meios pelos quais os professores se servem para responder à terceira fase, que é o currículo moldado pelos professores e que, como o próprio nome diz, é planejado pelos docentes. Nesse nível, o professor pode atuar como agente ativo e muito decisivo na concretização dos conteúdos e significados dos currículos, uma vez que procura responder aos problemas concretos que lhes apresenta o processo de ensino e aprendizagem. Nesse intento, referendam-se nos materiais prescritos e, também, em sua cultura profissional.

A quarta fase refere-se ao currículo em ação, momento caracterizado pela prática concreta, guiada pelos esquemas teóricos e práticos do professor como elementos que sustentam a ação pedagógica. Essa é a prática que pode se constituir e tornar-se orientadora do projeto educativo dos estudantes que frequentam essas escolas. As demais fases caracterizam-se como currículo realizado. Em outras palavras, são consequências da prática ou efeitos complexos de diversos tipos: cognitivos, afetivo, social, moral, ou os esperados rendimentos nos testes.

A sexta e última fase é o currículo avaliado, momento em que se reforça o significado definido na prática, o currículo desenvolvido. De fato, traz os elementos definidores da formação do aluno e exprime mais claramente a intencionalidade educativa.

Podemos entender que os professores pautam-se nos PCN, na MCR, ou na MC/SME, sobretudo por assumirem a responsabilidade em garantir que seus alunos sejam capazes de atingir os objetivos propostos pela política de avalição, saindo-se bem nos testes de rendimento. Nesse caso, trabalhar com as disciplinas e conteúdos que caem na PB torna-se praticamente uma obrigatoriedade. Notamos, pelos relatos, o empenho despendido pelos docentes nesse sentido. Visualiza-se, assim, indução ao conhecimento básico, sobretudo por encaminharem seus esforços para dar conta da PB, sob o risco de causar o estreitamento curricular produzido pela mesma.

Para identificar os 35 professores pedagogos, regentes, que ministram todos os componentes curriculares nas turmas de $5^{\circ}$ ano, utilizamos as letras PU, enumerados de 1 a 35 . Para os professores que ministram aulas em uma das áreas do currículo, geralmente com licenciaturas em Língua Portuguesa e Matemática, nesse caso, foram utilizadas as letras PA, enumerados de 1 a 20.

O plano de ensino altera porque a gente tem que trabalhar os descritores da PB, então você planejou para o ano determinado conteúdo, mas em função do que vai ser cobrado na PB, tem que centrar o que está ali, acaba alterando, sim. Você não deixa de trabalhar os conteúdos principais que têm que ser trabalhados, mas tem que focar mais nos que são cobrados. As vezes os prepara, treinando para a prova. Se não tivesse a prova, a metodologia seria outra, estaria conduzindo aquele conteúdo para que os alunos compreendessem da melhor maneira possivel [...] (Entrevista, PU08, 2013).

Exatamente, a partir do momento em que foi iniciada a avaliação do IDEB, os conteúdos já são em cima deles, inclusive livros que vêm do INEP, lá de Brasília, 99\% dos livros já são adaptados para essa função. Os livros de

Práxis Educativa, Ponta Grossa, p. 641-656, v. 11, n. 3, set./dez. 2016 Disponível em: < http://www.revistas2.uepg.br/index.php/praxiseducativa > 
Matemática são todos contextualizados para prova, o livro não é em projeto, nós montamos o projeto, adequamos as atividades no projeto pra trabalhar com as crianças, pra que não fuja da realidade da PB, das questões que estão ali (Entrevista, PU04, 2013).

O plano de ensino nós discutimos e organizamos para o ano, aí vêm cursos e normas da Secretaria e falam que o que você planejou e ensina, mais isso "aqui" é prioridade, então, ocorre uma mudança. Esses tempos en estava fazendo meu plano de aula e falaram para eu ir por outro lado porque aquilo que ia cair na PB. E naquele momento, para mim, aquilo era importante. Eu acabo deixando de lado algumas situações para fazerer o que o sistema pede (Entrevista, PA18, 2013).

A mudança veio porque, agora, você não tem mais como faz̧er avaliação na escola, você tem que avaliar o aluno, português e matemática, esquece o resto, ou seja, os outros professores, as outras matérias, não existem mais, e até para rede, você vai olhar para a escola como? A escola que sai bem no IDEB tem uma verba melhor, é bem vista. No geral, você olha assim, o cuidado que tem na escola " $x$ " é porque a escola está mal no IDEB, vamos ter que levantá-la. Fica parecendo que são um monte de menininhos dementes ou pessoas não qualificadas que estão lá, vão [técnicos] para lá para mudar, vão [sic] sair um monte de gente porque está mal no IDEB, mas isso é só com um tempinho depois que passou o IDEB, espera 6 meses, esquece tudo [...] (Entrevista, PA19, 2013).

Para Freitas et al. (2012, p. 389), "avaliações geram tradições. Dirigem o olhar de professores, administradores, estudantes". Sob este ponto de vista, podemos dizer que esses materiais, utilizados para o planejamento curricular, tiveram seu uso ampliado na execução dos docentes; porém, de forma a restringir a qualidade educativa que almejamos.

A Secretaria Municipal de Educação (SME), ainda que tenha adotado a política de avaliação do governo federal, mantém, em seu currículo oficial, outras áreas do conhecimento. A matriz curricular oficial (cf. Port. N.001/2013) que a SME propõe para o $5^{\circ}$ ano é organizada por áreas do conhecimento. Língua Portuguesa é uma das disciplinas que compõe a área de Linguagens, Códigos e suas Tecnologias. Esta área contempla Educação Física e Artes.

A partir desse currículo, os técnicos elaboraram e enviaram, às escolas, uma matriz curricular mais completa, já que propõe, também, o trabalho com outras áreas do conhecimento. Entretanto, os professores admitem que estejam colocando em desenvolvimento um currículo modelado na conformação com as matrizes de referências da avaliação externa, e pontuam que o trabalho em sala focaliza, com mais ênfase, as disciplinas e os conteúdos escolares requeridos nos testes padronizados. A justificativa é óbvia: é por esses conteúdos e essas disciplinas e não outras, que são pressionados, cobrados e responsabilizados.

Nesse sentido, indagados sobre a matriz curricular, e $43 \%$ dos professores do $5^{\circ}$ ano assinalaram que a disciplina de Língua Portuguesa e a de Matemática, em sua prática, ganharam mais destaque e importância por causa da Prova Brasil, e alguns assumem que também essas passaram a ter maior carga horária.

Uma vez que se utilizam essas duas disciplinas, elas são muito mais destacadas (Entrevista, PA15, 2013).

Ganhou mais destaque e mais importância, mas tem a mesma carga horária (Entrevistas, PA18; PU28; PU26, 2013).

Os destaques para estas duas áreas já são colocados, na prática, como mais importante no dia a dia (Entrevista, PU08, 2013).

A carga horária de quatro aulas semanais passou a ser de cinco aulas semanais (Entrevista, PU16, 2013).

A carga horária oficial não mudou, e sim em sala de aula (Entrevista, PU27, 2013).

Práxis Educativa, Ponta Grossa, p. 641-656, v. 11, n. 3, set./dez. 2016 Disponível em: <http://www.revistas2.uepg.br/index.php/praxiseducativa> 
Aumento de carga horária não, mas a atenção nessas disciplinas (Entrevista, PU34, 2013).

[...] agora estou trabalhando mais português e matemática, justamente por causa da prova (Entrevista, PU02, 2013).

Para Goodson (2008), a sustentabilidade no mundo do currículo escolar está intimamente relacionada com a recepção que esse currículo venha a ter nos públicos externos. Nesse sentido, o mesmo ocorre com as disciplinas escolares, que também estão em harmonia com grupos de poder externos. Por que alguns conhecimentos são induzidos e outros explicitamente sonegados?

Vale ressaltar que 55\% dos sujeitos afirmaram que as disciplinas de Língua Portuguesa e Matemática mantêm a mesma importância e carga horária. Salientamos que, a esse propósito, apenas um dos sujeitos deixou a questão em branco, o que nos permite concluir que nenhum dos demais assumiu que essas disciplinas diminuíram em importância e carga horária.

Defesa em favor de um currículo mais alargado também houve:

Eu considero primordial desenvolver outras potencialidades que não estão dentro do currículo. Tem que ter Português, Matemática, História, Geografia, Ciências, Ensino religioso... por que que tem Ensino religioso se não pode falar nada...? Você tem que falar sobre solidariedade, isso a gente fala no dia a dia, entendeu? (Entrevista, PU05, 2013).

Procurando ampliar o entendimento sobre essa questão, indagamos como estão organizando o currículo na prática escolar. Dos sujeitos entrevistados, $25 \%$ afirmaram que o foco é em Língua Portuguesa e Matemática; 64\%, que focam em todas as disciplinas, nenhuma sendo desprezada; e 15\% revelaram que algumas disciplinas foram prejudicadas. Apesar de alguns professores afirmarem não desprezar nenhuma das disciplinas, quando indagados sobre quais disciplinas ficaram prejudicadas, percebemos contradição no discurso, pois declararam que:

Artes, História e Geografia (Entrevista, PA11, 2013);

História, Geografia, Artes e Educação Física (Entrevista, PA12, 2013);

História, Geografia, Ciências e Religião (Entrevista, PU06, 2013).

Ressaltamos que não somos contrários ao trabalho com a dimensão cognitiva no currículo escolar. Porém, a ênfase dada pela avaliação em larga escala, aos aspectos cognitivos de Língua Portuguesa e Matemática, tem induzido ao estreitamento curricular, especialmente porque promove situações em que ensinar e aprender para o teste seja a razão principal do fazer docente. Os professores relataram que os esforços são concentrados nos conteúdos e nas disciplinas que serão avaliadas, chegando ao extremo de desconsiderar as demais, mesmo que altamente relevantes para a formação do estudante, como as que foram citadas.

Recomendamos que, além das disciplinas, há que se observar conteúdos que a PB propõe. Língua Portuguesa sim, mas por que simplesmente leitura e não a escrita?

As provas bimestrais da escola são subjetivas. Eu acredito que a PB teria que ter questões dissertativas e objetivas. Eles (os alunos) têm muitas dificuldades ortográficas, dificuldades de organizarem, mas para falar do conhecimento deveria saber se o aluno sabe dissertar sobre o tema... é mais dificil, mas eu acho que é difícil para eles corrigirem as provas do Brasil inteiro, mas se fizessem amostragem em termos de provas subjetivas, o resultado seria diferente (Entrevista, PU34, 2013).

E o que esses alunos realmente pensam? Que será desses alunos assim, sempre condicionados? Não formula uma questão objetiva... sem escrever, ...sem colocar no papel o que ele pensa. Porque diminuiu a produção de texto e 
acirrou mais a leitura. Principalmente porque a produção de texto dá trabalho. Dá muito trabalho para o aluno pensar, argumentar, e para o professor acompanhar, ou seja, corrigir toda essa producão (Entrevista, PU12, 2013).

O texto escrito é o principal instrumento de circulação do conhecimento. Se, por um lado, a leitura é indispensável para o próprio processo de escolarização e as dificuldades relacionadas à leitura provocam decorrências negativas na aprendizagem das demais áreas de conhecimento, por outro, a escrita é um conhecimento que dá poder aos estudantes. Compreendemos como estreitamento curricular o foco em duas disciplinas, especialmente ao apresentar, ainda, restrição interna de conteúdos importantes nessas mesmas disciplinas escolares, como o caso da escrita.

Para ajudar os alunos a desenvolver diferentes finalidades de leitura, presentes na escola e fora dela, é preciso que os alunos tomem consciência sobre os diferentes modos de ler, relacionados aos diferentes propósitos de leitura na sociedade. Lembramos que o currículo nunca é neutro, nele há tendenciosidades, muitas vezes bem explícitas, noutras ocultas. Nesse sentido, a ênfase nas disciplinas e conteúdos considerados importantes e o descaso com os demais, dandolhe ares de dispensáveis, vão desnudando os reais interesses acerca do currículo e, consequentemente, da educação que ensejam para os estudantes.

O campo da linguagem que defendemos é amplo, falamos em linguagens e todas elas, inclusive a linguagem matemática, que está presente em diversas atividades humanas, como artes, músicas, informática, nas situações práticas do dia a dia, entre outras. É praticamente impossível pensar o contexto atual sem que se pense e estabeleça relações com múltiplas áreas do conhecimento. Desse modo, reiteramos que valorizar a importância e o domínio da linguagem em uma ou duas disciplinas é limitar, em demasia, o currículo escolar.

As estratégias metodológicas que os sujeitos afirmam empregar para o desenvolvimento do currículo foram as seguintes: $62 \%$ trabalham com projetos; $9 \%$, temas geradores; $28 \%$ alegaram trabalhar de forma interdisciplinar; menos de $10 \%$ admitiram reportar-se a outras formas.

A gente faz o projeto, mas fica bonito só no papel. No final cada um dá aula do seu jeito. Isso não é projeto nada, isso é projeto só no papel. Chega à sala de aula, cada um faz o que quer, do jeito que quer (Entrevista, PU27, 2013).

Baseado na PB, mas nós trabalhamos também com projetos. Escolhemos o tema do projeto, o subtema, tem que ter todo o conteúdo da PB. Português e Matemática totalmente voltadas à PB. Se o professor tiver disponibilidade funciona, porque o professor tem que esquecer o projeto; dependendo o tema do projeto, ele esquece o projeto e até chegar a PB, esse projeto está morto, é só fantasia (Entrevista, PA19, 2013).

Apesar da maioria dos sujeitos afirmarem que trabalham com a metodologia de projetos, percebemos que estes, quando existem, são adequados e ajustados à PB. Compreendemos que a centralização em Língua Portuguesa e Matemática, por meio da $\mathrm{PB}$, não é compatível com metodologia de projetos. A principal influência que os entrevistados explicitaram a respeito das estratégias metodológicas e conteúdos foi a indução a um trabalho com disciplinas isoladas e estanques. E o mais nocivo é que, dessa forma, inibe toda e qualquer iniciativa de um trabalho mais criativo e dinâmico na prática pedagógica dessas escolas. Coaduno com a afirmação de Freitas, para quem

O direito à formação ampla e contextualizada que todo ser humano deve ter é reduzido ao direito de aprender o "básico" expresso nas matrizes de referência dos exames nacionais, assumido ali como o domínio que é considerado "adequado" para uma dada série

Práxis Educativa, Ponta Grossa, p. 641-656, v. 11, n. 3, set./dez. 2016 Disponível em: < http://www.revistas2.uepg.br/index.php/praxiseducativa > 
escolar nas disciplinas avaliadas - não por acaso as que estão mais diretamente ligadas às necessidades dos processos produtivos: leitura, matemática e ciências. Convém enfatizar que são as matrizes de referência dos exames e não o curriculo prescrito, a base nacional comum, que definem o que será considerado como "básico". (FREITAS, 2014, p. 1090, grifos do autor).

Indagamos, ainda, aos professores que lecionam nas turmas do $5^{\circ}$ ano, sobre a necessidade e a realização de simulados. O equivalente a 40,7\% alegou ser preciso muito treino, $30 \%$ revelaram que um pouco de treino era bom, e $20 \%$ afirmaram não precisar de treino. Vale salientar que houve, por parte de alguns sujeitos, indagações e tentativas de explicação sobre a diferença entre ensinar e treinar.

Demos vários simulados (Questionário, PA3, 2013).

Porque os alunos não estão acostumados com esse tipo de avaliação (Questionário, PA18 - EA3, 2013).

Acaba melhorando o aprendizado do aluno (Questionário, PA19, 2013).

Tem que doutrinar (Questionário, PU05, 2013).

A prova é de múltipla escolba e preenchimento do gabarito (Questionário PU11, PU12, 2013).

Pela dificuldade de marcar em gabarito (Questionário, PA15, 2013).

Para evitar que a prova seja vista como uma novidade e atrapalhe o desempenho dos alunos (Questionário, PU15, 2013).

Porque o adulto, quando vai prestar concurso, ele foca no estudo para alcançar seu objetivo de vida e êxito (Questionário, PU18, 2013).

Precisamos treinar e muito os simulados. As crianças chegam ao quinto ano sem nunca terem visto um gabarito. Ai cai na prova o gabarito (Entrevista, PA19, 2013);

Nós temos feito muitas atividades, é [sic] provinhas, testes, simulados, acho que nós já firzemos cinco simulados do comeģo do ano até aqui. A gente far. o simulado, a tabulação dos dados, certinho, e vê se o aluno se desenvolveu bem, e no que não se desenvolveu bem. Tem-se [sic] uma questão que a maioria não acertou, então a gente vai procurar tentar fazer um trabalho em cima daquele assunto para tentar melhorar. E outra coisa que nós pedimos, no simulado, sempre, é que mesmo que seja para marcar múltipla escolha, que o aluno trabalhe a questão. No simulado, até agora, nós exigimos o tempo, mas que também trabalhe a questão. Então, como a Prova Brasil tem um tempo de 25 minutos para cada bloco de questões, nós colocamos o bloco, nós damos 15 minutos a mais, 40 minutos para cada bloco, para que eles desenvolvam as questões e depois marquem a resposta certa (Entrevista, PU05, 2013);

Eu acho que a escola com alto IDEB é que a que treinou melhor os alunos. Eu propus fazer um treinamento militar, desde o comego do ano até o final, propus até para a escola, se quisesse que eu pegasse as 3 turmas, en pegava e fazia um treinamento com eles. Ai a... Coordenadora falou 'não, mas nós não podemos falar isso', eu falei 'podemos sim'. Porque o que acontece na China, que superou o Japão no IDEB, é treinamento militar em relação à Matemática, eles colocam 50 alunos na sala e os alunos tem que repetir a fórmula até incorporar a fórmula, e depois, quando vai resolver a fórmula está incorporada, resolve, fa\%. Método Kumon, o que é? É repetição até a pessoa incorporar. Então eu falei isso na secretaria, numa reunião, o pessoal falou 'não, não, não podemos falar isso', eu falei 'não podemos falar, mas está sendo praticado'. Na escola, eu sei de escola que, não vale a pena citar o nome, mas en sei de escola que treinou os alunos para fazer o IDEB, ou a Prova Brasil. E aqueles alunos que não conseguiram acompanhar no treinamento, esses alunos foram convidados a não participar da Prova

Práxis Educativa, Ponta Grossa, p. 641-656, v. 11, n. 3, set./dez. 2016 Disponível em: <http://www.revistas2.uepg.br/index.php/praxiseducativa> 
Brasil. Então participaram aqueles alunos que acompanhavam o treinamento e podiam sair bem no simulado e elevar o IDEB da escola (Entrevista, PU05, 2013).

Alguns sujeitos admitiram que não é necessário treinar os alunos porque:

As questões não dependem de treino, e sim de interpretação (Questionário, PA07, 2013);

Pois o conteńdo de sala já trabalha com todas as matrizes da Prova Brasil (Questionário, PU04, 2013);

O conbecimento não se treina, se adquire (Questionário, PU16, 2013);

Treino, a meu ver, não é aprendizado (Questionário, PU20, 2013);

Porque a preocupação é aferir o conbecimento real (Questionário, PU31, 2013);

Não realizamos treinamentos, pois estamos sempre preocupados no nosso trabalho normal (Questionário, PU32, 2013);

Treinar, treinar só não. Mas ensinar o gabarito, a escolba e o conteúdo (Questionário, PU34, 2013).

Ampliamos as alternativas indagando sobre o tempo disponibilizado para o treino; 14 dos entrevistados admitiram que até 2 horas por semana, 8 deles disseram ser mais de 4 horas semanais, e 15 permaneceram afirmando que não realizam treinos. Os argumentos para a realização do treinamento foram os seguintes:

- Até 2 horas semanais:

Para utilizar melhor o tempo na hora da PB (Questionário, PU12, 2013);

Um simulado por bimestre para treinar num ambiente próximo do real (Questionário, PU15, 2013).

- 4 ou mais horas por semana:

São aplicados simulados para acostumarem com as questões e marcação (Questionário, PA15, 2013);

Quando se aproxima (Questionário, PU06, 2013);

Para utilizar melhor o tempo da prova (Questionário, PU11, 2013).

- Não realizo treinamento:

O que realizo é a conscientização de que há várias formas de se avaliar e a prova é uma delas, e como é exigido é bom que aprenda (Questionário, PA10, 2013);

Não gasto muito tempo, há preparação desde o começo do $1^{\circ}$ ciclo (Questionário, PU01, 2013);

Pretendo utilizar, não treinamos questões e atividades de múltipla escolha (Questionário, PU02, 2013);

Porque se faz o trabalho integrado, fazendo uma ligação (Questionário, PU32, 2013);

Meu trabalho é contínu, todo o meu planejamento é realizado de forma a levar os alunos a refletirem, procuro prepará-los para a vida futura (Questionário, PA15, 2013);

Faz.provas com conteúdos aproximando-se das PB, mas sem [sic] só o treinamento (Questionário, PU34, 2013).

Práxis Educativa, Ponta Grossa, p. 641-656, v. 11, n. 3, set./dez. 2016 Disponível em: < http://www.revistas2.uepg.br/index.php/praxiseducativa > 
Notamos que os treinamentos para os testes têm o percentual maior que o admitido, talvez pelo fato de alguns sujeitos sentirem-se constrangidos em admiti-lo.

A pressão exercida, nas décadas anteriores, era para que os alunos, mesmo os que não conseguissem aprender, passassem de ano e/ou ciclos (FREITAS, 2004). Ainda que resultasse em eliminação adiada, atualmente a pressão é para que treinem os alunos para melhorarem o rendimento na $\mathrm{PB}$, mesmo que a melhor nota não garanta aprendizagens. Troca-se o chicote, mas mantém-se o castigo, e a perversa lógica da exclusão escolar permanece.

Compreendemos que, nesse cenário, há professores, de certo modo, confortáveis quanto às avaliações. Há os que estão desconfortáveis e os que aparentam certo distanciamento ou indiferença em relação a elas. Contudo, é possível afirmar que a política de avaliação está entranhada nessas escolas, de forma indutora, interferindo no trabalho docente e prescrevendo o currículo escolar.

Nesse caso, consideramos que o controle curricular tem, como principal instrumento, um sistema de avaliação que funciona como legitimador de determinados conjuntos de saberes e, portanto, poderes. Estudiosos da área, tais como Moreira (1995), Gentili (1994; 1995), Silva (1994), Apple (2005), Freitas (2009), Freitas et al. 2012) e Souza (2009) vêm alertando que tais políticas são de cunho neoliberal, produtos da nova ordem internacional, que alterou o modelo das cobranças exigidas pelo capital, imprimindo sua lógica também no campo educacional.

Entendemos ser imperativo questionar o conhecimento curricular fixado, as posições unilaterais que os impõem, e porque privilegia um único ponto de vista como verdade absoluta, uma única fonte de conhecimentos e poucas formas de aprender. A hierarquização e a restrição do currículo são claramente ressaltadas nessa política de avaliação. É preciso refletir sobre o lugar que ocupam essas disciplinas, quando se tem por objetivo a formação integral dos alunos. Muitas vezes, a preocupação tão somente com a empregabilidade do estudante não busca resposta para a principal pergunta: Que homem se quer formar?

"A política sobre o currículo é um condicionamento da realidade prática da educação que deve ser incorporada ao discurso sobre currículo". Desse modo, "é um campo ordenador decisivo, com repercussões muito diretas sobre essa prática e sobre o papel e margem de atuação que os professores e os alunos têm da mesma” (GIMENO SACRISTÁN, 2000, p. 107).

Diante do exposto, não é de se estranhar que o planejamento, planos de aula, e outras situações próprias da prática pedagógica tenham igualmente sido alterados. Nesse cenário, os professores, na ânsia que seus alunos logrem resultados favoráveis nos testes, tomam o recorte da PB como se fosse a totalidade do conhecimento a ser alcançado. Como indagou um professor, referindo-se aos conteúdos da PB: "Esse é o limite?”.

Compreendemos, por básico, o mínimo, mas, no cenário dos testes, o básico está sendo entendido como máximo. Assistimos, desse modo, à implementação de um currículo pautado no básico. Tomando de empréstimo o vocabulário dos empresários, podemos afirmar que os conhecimentos que a PB está tomando dos sujeitos está sendo teto e não como piso. Gimeno Sacristán (2000) adverte que a regulação de mínimos denota, de forma mais clara, o projeto de socialização ao qual se propõe o currículo.

É notório que os testes da PB têm contribuído para tirar de cena os aspectos curriculares, dimensões, disciplinas e conteúdos, não passíveis de mensuração. Aspectos importantes que também deveriam compor o processo de formação dos estudantes. Essa aceitação da matriz de referência da avaliação, como parâmetro principal para a elaboração do currículo escolar, é um 
artifício do qual nem professores, nem gestores e nem mesmo alunos escapam. Ocorre de modo, aparentemente, passivo, como se houvesse consenso.

Como os professores não conseguem ser indiferentes aos resultados e levam em consideração as classificações do ranking, acabam por alterar sua prática pedagógica, em uma tentativa de melhorar sua imagem como professor/a e, ao se posicionar dessa forma, pode fazer emergir a cultura da performatividade, como denomina Ball (2004).

Ainda que saibamos que as escolas são instituições complexas que apresentam similaridades e diferenças entre si, em outras palavras, cada uma concebe e resolve seus problemas de maneiras distintas uma das outras. A conjuntura apelativa das avaliações externas, por meio das cobranças e pressões exercidas nas escolas e nos profissionais destas, ocasionando intervenções sistemáticas, tem provocado mudanças em suas práticas.

Frente a essa realidade imposta às escolas pelas avaliações externas, observamos algumas evidências que permitem afirmar que os testes padronizados estão indicando quais conhecimentos curriculares são relevantes, delimitando, por extensão, o que deve ou não ser ensinado nas escolas.

Após levantar os impactos que as avaliações produzem nas escolas, analisamos essa medida potente para prescrever o planejamento curricular em função das disciplinas da PB. Assim, os resultados parecem ter um fim em si mesmo, pois, na prática, impulsionam a busca da melhoria nos resultados da prova, ainda que essa melhoria não signifique aprendizagem para os alunos. É como se os dados dirigissem o olhar para o próprio dado, afiançando o uso de conhecimentos legitimados na PB. Isto significa dizer que, de maneira velada, parece que se admite o desenvolvimento do currículo centrado tão somente na ação de melhorar o rendimento dos estudantes na PB. Nesse caso, não se pode estranhar a indução fortemente marcada no que denominamos de metodologia do treino.

As situações restritivas, que também compõem os aspectos que têm impacto no currículo configuram uma limitação resultante da centralidade dada à dimensão cognitiva, em detrimento das demais dimensões. Restrição na própria dimensão cognitiva ao eleger língua portuguesa e matemática como prioritárias, dentre um leque de disciplinas. Restrição até mesmo de competências, habilidades e/ou conteúdos, por exemplo, a valorização da leitura e não da escrita. Compreendemos a existência de um efeito simbólico poderoso nessas restrições.

O quadro esboçado fornece alguns indicativos que postulam a qualidade educacional que essas avaliações imprimem nas escolas. Se tomarmos por referência a trajetória que a avaliação percorre, considerando as finalidades a que se propõem e os impactos que vem acarretando nos espaços escolares, especialmente para os professores, constatamos que são tomadas certas decisões, e assumidas determinadas prioridades, que produzem efeitos bem diferentes daqueles que são anunciados pela política de avaliação.

Além disso, culturalmente, a ação de avaliar pressupõe e cria expectativa de representação do real. Assim entendida, torna-se capaz de evidenciar verdades difíceis de serem questionadas sobre a realidade, tanto na aprendizagem do aluno quanto nas avaliações em larga escala.

Temos clareza de que há um currículo oficial em disputa. Embora a rede municipal tenha determinações curriculares formalmente mais democratizadas em vários aspectos do currículo (definição dos conteúdos curriculares, estratégias metodológicas mais inovadoras, da carga horária dos componentes e das áreas de conhecimento, por exemplo), percebemos que há “[...] forças agindo sobre a escola que podem tornar tais escolhas praticamente sem significado" 
(APPLE, 1999, p. 179). Compreendemos que as avaliações externas em larga escala constituíramse em uma dessas forças.

Desse modo, alargar o currículo vislumbrando uma ampla formação para os estudantes não integra as dimensões priorizadas nessas avaliações, que são orientadas por políticas neoliberais.

\section{Algumas considerações}

Não somos contrários à avaliação externa. No entanto, percebemos que a política de avaliação, da forma que está ocorrendo, especialmente a PB/IDEB, tem contribuído para manter os profissionais da educação presos à teia de responsabilização, meritocracia e desprofissionalização.

Se, algumas décadas atrás, se entendia por bom professor aquele que reprovava mais, atualmente, no contexto dos testes, bom professor é o que consegue os melhores resultados nas avaliações externas em larga escala. Desse modo, além do estreitamento curricular, há, ainda, o estreitamento do papel do docente, incrementado pela política de avaliação, uma vez que a responsabilização, atribuída aos professores pela política de avaliação externa, imputa-lhes papel de cunho técnico e de dependência, de forma a dificultar-lhes ações mais ativas, reflexivas, coletivas e autônomas acerca do seu próprio trabalho e das finalidades da educação.

Compreendemos que a política de avaliação induz as escolas e seus profissionais a uma incessante busca pela melhoria do rendimento dos alunos e, consequentemente, do desempenho escolar. Assim, os professores têm focado o trabalho nas disciplinas e conteúdos da PB. Decorre dessa situação a hierarquização curricular ao supervalorizar as disciplinas de língua portuguesa e matemática, em detrimento das outras, históricas e culturalmente colocadas nos currículos escolares. Ocorre, assim, o estreitamento do currículo, ao serem focadas as disciplinas cujos conteúdos constam na $\mathrm{PB}$, em detrimento das disciplinas citadas acima pelos sujeitos. Desse modo, alargar o currículo para atuar em dimensões que tornem as experiências de ensino e aprendizagens mais ricas e significativas, de forma a contribuir para a formação de um estudante mais criativo, questionador, não integra as dimensões priorizadas nesse modelo avaliativo, pelas consequências que delas decorrem.

Admitimos a interferência da avaliação externa em larga escala na configuração do currículo escolar, induzindo a um currículo prescrito pela matriz de referência avaliativa, currículo restrito, hierárquico e unidimensional, frontalmente em oposição a um currículo ampliado, interdisciplinar e multidimensional.

Além de padronizar o currículo, levando ao estreitamento e não à sua ampliação e, desse modo, informar o básico que se deve ensinar aos alunos nessas escolas, transformando o piso em teto, a PB contribuiu para introduzir uma metodologia desvirtuada para o treinamento. Adiciona-se a isso a relação de dependência com os materiais relativos à PB para elaborar o planejamento curricular anual e as ações de ensino e aprendizagem, o que compõe um contexto educacional distante de uma qualidade educacional socialmente relevante.

Por fim, ainda que entendamos que as contribuições aqui tecidas não são conclusivas, esperamos que possam instigar e contribuir para que novas investigações sejam realizadas, pois entendemos que, para a compreensão do objeto estudado, há muito para ser desvelado.

Nesse cenário, indicamos como imprescindível e urgente propor, aos professores, formações que oportunizem questionamentos sobre as finalidades da educação, do currículo e 
reflexões sobre o papel docente. É preciso delegar, aos professores e demais profissionais que trabalham nas instituições de ensino, autonomia para (re)pensarem e (re)elaborarem o currículo escolar.

Nesse momento, é urgente a desocultação da qualidade, subjugada na avaliação externa em larga escala e a consequente desocultação do currículo, pois nele se encerra a intenção, embora velada, da qualidade supostamente a ser garantida por meio dessa política. E, a nosso ver, a qualidade impressa nessas políticas aposta em uma escola como um bem de serviço.

Finalizamos com as seguintes afirmações, resultado deste e de outros estudos: percebemos, nessas últimas décadas, o investimento em um discurso de escola como direito, obrigatória e inclusiva que, contraditoriamente, por mais que se reconfigure, está permanentemente a excluir. A forma escola, apesar da aparente metamorfose e da falácia de melhoria da qualidade, ainda não é para todos, indistintamente, como se queira fazer acreditar.

\section{Referências}

APPLE, M. Educação e poder. Trad. M. C. Monteiro. Porto Alegre: Artes Médicas, 1999.

APPLE, M. A Política do Conhecimento Oficial: faz sentido a idéia de um currículo nacional? In: MOREIRA, A. F. SILVA, T. T (Orgs.) Currículo, cultura e sociedade. 8. ed. São Paulo, Cortez, 2005.

BALL, S. J. Performatividade, privatização e o pós-estado do bem-estar. Revista Educação e Sociedade, Campinas, v. 25, n. 89, p. 1105-1126, set./dez. 2004. DOI: 10.1590/s010173302004000400002

BARDIN, L. Análise de conteúdo. Lisboa: Portugal. Edições 70 LDA, 2012.

BORDIEU, P. A reprodução. Rio de Janeiro: Francisco Alves, 1992.

CASTRO, A. M. D. A.; LAUANDE, M. F. R. F. Formação de professores da educação básica em nível superior: uma exigência da sociedade da comunicação e da informação. In: CHAVES, V. L. J.; NETO, A. C.; NASCIMENTO, I. (Org.). Políticas para a educação superior no Brasil: velhos temas e novos desafios. São Paulo: Xamã, 2009, p. 145-172.

CIAVATTA, M. O mundo do trabalho em imagens. Rio de Janeiro: DP\&A, 2002.

DURLI, Z.; SCHNEIDER, M. P. Regulação do currículo no Ensino Fundamental de 9 anos. Contrapontos, Itajaí, v. 11, n. 2, p. 170-178, maio/ago. 2011.

FREITAS, L. C. A Avaliação e as reformas dos anos 90: novas formas de exclusão, velhas formas de subordinação. Educação \& Sociedade, Campinas, v. 25, n. 86, p. 3-6, abr. 2004. DOI: 10.1590/S0101-73302004000100008.

FREITAS, L. C; MALAVASI, M.M. S.; SORDI, M. R. L.; MENDES, G. S. C. V; ALMEIDA, L. C. (Orgs.). Avaliação e Políticas Públicas Educacionais: ensaios contrarregulatórios em debate. Campinas: Edições Leitura Crítica, 2012. 
FREITAS, L. C. Os reformadores empresariais da educação e a disputa pelo controle do processo pedagógico da escola. Educação \& Sociedade, Campinas, v. 35, n. 129, p. 1085-1114, out./dez. 2014. DOI 10.1590/es0101-73302014143817

GENTILI, P. O Discurso da "qualidade" como nova retórica conservadora no campo educacional. In: GENTILI, P.; SILVA, T. T. (Org.). Neoliberalismo, qualidade total e educação. Petrópolis: Vozes, 1994.

GIMENO SACRISTÁN, G. O currículo: uma reflexão sobre a prática. Tradução de Ernani F. da F. Rosa. 3. ed. Porto Alegre: ArtMed, 2000.

GOODSON, I. F. Currículo, narrativa e o futuro social. Revista Brasileira de Educação, Rio de Janeiro, v. 12, n. 35, p. 241-252, maio/ago. 2007. DOI: 10.1590/s1413-24782007000200005

GOODSON, I. F. As políticas de currículo e de escolarização: abordagens históricas. Petrópolis, RJ: Vozes, 2008.

MOREIRA, A. F. Neoliberalismo, currículo nacional e avaliação. In: SILVA, L. H. da; AZEVEDO, J. C. (Orgs.). Reestruturação curricular: teoria e prática no cotidiano escolar. Petrópolis: Vozes, 1995.

PACHECO, J. A. Teorias curriculares: políticas, lógicas e processos de regulação regional das práticas curriculares. Conferência realizada no âmbito do Seminário "O Currículo Regional", Terceira, Açores, 4 de Setembro de 2003. CD-room.

SANTOS, L. L. C. P. As duas faces da avaliação. In: FAVACHO, A. M. P.; PACHECO, J. A.;

SALES, S. R. (Orgs.). Currículo: Conhecimento e Avaliação divergências e tensões. Curitiba: CRV, 2013.

SILVA, T. T. da. A "nova" direita e as transformações na pedagogia da política e na política da pedagogia. In: GENTILI, P.; SILVA, T. T. da. (Orgs.). Neoliberalismo, qualidade total e educação. Petrópolis: Vozes, 1994.

SILVA, T. T. da. Documentos de Identidade: uma introdução às teorias do currículo. 2 ed. Belo Horizonte: Autêntica, 2007.

SOARES, J. F., XAVIER, F. P. Pressupostos educacionais e estatísticas do IDEB. Educação \& Sociedade, Campinas, v. 34, n. 124, p. 903-923, jul./set. 2013. DOI: 10.1590/s010173302013000300013

SOUZA, S. Z. L. Avaliação e gestão da educação básica. In: DOURADO, L. Políticas e gestão da educação no Brasil: novos marcos regulatórios. São Paulo: Xamã, 2009.

YOUNG, M. O futuro da educação em uma sociedade do conhecimento: a defesa radical de um currículo disciplinar. Cadernos de Educação, Pelotas, n. 38, 395 - 416, jan./abr. 2011. 